\title{
PROFESSORES: ENTRE O PRAZER DE ENSINAR E A INSATISFAÇÃO DAS CONDIÇÕES DE TRABALHO
}

\section{TEACHERS: BETWEEN THE PLEASURE OF TEACHING AND THE DISSATISFACTION WITH THE WORKING CONDITIONS}

\section{DOCENTES: ENTRE EL PLACER DE ENSEÑAR Y LA INSATISFACCIÓN DE LAS CONDICIONES DE TRABAJO}

\author{
José Alexandre da Silva ${ }^{1}$ \\ https://orcid.org/0000-0003-0913-4534
}

DOTTA, Leanete Thomas. Representações sociais do ser professor. Campinas: Alínea, 2006.

Nos dias atuais é bastante fácil capturar artigos em revistas científicas digitais e encontrar até mesmo livros que utilizam o termo representações de forma indevida. É como se o conceito estivesse tão em voga, que apenas a sua mera associação ao título do livro ou artigo dispensasse a utilização de todos os procedimentos metodológicos necessários para a constituição de um objeto de pesquisa em representações sociais. Pode-se até dizer que está havendo um abuso no emprego do conceito, considerando que em algumas pesquisas, esse não é utilizado adequadamente, o que não acontece no livro ora resenhado.

A explanação que a autora realiza no capítulo teórico é bem fundamentada, sendo o ponto forte do livro. Explica o surgimento da TRS, desenvolve o conceito de forma detalhada, com base em Moscovici, Abric, Jodelet e outros estudiosos, e consegue fazer isso não de forma rebuscada tornando a leitura agradável. É interessante destacar uma citação de Moscovici, (DOTTA, p. 17), considerando que o mesmo já se recusou à uma definição do conceito receando seu empobrecimento: "[...] a representação social é um corpus organizado de conhecimentos e uma das atividades psíquicas graças as quais os homens tornam inteligível a realidade física e social, inserem-se num grupo ou numa ligação cotidiana de trocas e liberam os poderes de sua imaginação."

${ }^{1}$ Mestrando em Ensino de História pela UEPG, Professor de História (Seed - PR), Ponta Grossa - PR. alexandre875@hotmail.com 
Não há como falar em representação sem mencionar dois conceitos que estão ligados intrinsecamente a esse, a objetivação e a ancoragem: "Duplicar um sentido por uma figura abstrata, materializar um objeto abstrato, foi chamado de objetivação. Duplicar uma figura por um sentido, proporcionar um contexto inteligível ao objeto, interpretá-lo, foi denominado de ancoragem." A ancoragem por sua vez está relacionada com classificação e denominação (DOTTA, p. 20): "[...] o que não é classificado nem denominado é estranho, não existe [...]" já a objetivação (DOTTA, p. 22), é definida como que um processo: "[...] responsável pela transformação de um esquema conceitual em real, é a atribuição de uma contrapartida material a uma imagem." Vale ressaltar também a menção explícita à visão dimensional da TRS trazida por Moscovici, para que haja representação social é preciso encontrar três elementos: informação, imagem e atitudes (DOTTA, 2006, p. 26):

[...] a dimensão da informação está relacionada à organização dos conhecimentos que um grupo possui sobre um dado objeto social; a dimensão do campo de representação que remete à ideia de imagem, refere-se ao conteúdo concreto e limitado das proposições atinentes a um aspecto preciso do objeto da representação; e a dimensão da atitude é aquela que destaca a orientação global em relação ao objeto da representação social."

A autora enfatiza a utilização da TRS na França, na Argentina e no Brasil. Menciona ainda a pertinência do uso desse corpo teórico/metodológico no que diz respeito ao campo educacional. Frisa ainda a utilização de programas de computador, como o ALCESTE (programa que efetua análise de vocábulos) e o EVOC (programa utilizado para análise textual), para o processamento de dados. No seu capítulo intitulado "A Investigação", Dotta não é menos rigorosa. Também se ampara em vasta bibliografia, inclusive pesquisada no exterior, para descrever a trilha metodológica percorrida por outros autores. Fala dos processos mais utilizados de coleta de dados, como os questionários e as entrevistas e também descreve técnicas que são comumente associadas às representações sociais, como a Análise de Conteúdo. Entretanto, acreditamos que a caracterização do objeto merece ser observada mais de perto.

Logo no início da introdução podemos ler: "Essa dissertação teve como objeto de investigação as representações sociais sobre o ser professor de um grupo de professores do Ensino Médio da Rede Pública Estadual de Palotina" (DOTTA, 2006, p. 07). Na melhor descrição que temos do referido grupo de professores:

[...] quando fizermos uso das palavras professores, docentes e Rev. Fac. Educ. (Univ. do Estado de Mato Grosso), Vol. 33, Ano 18, № 1, p. 271-276, jan./jul., 2020. 
sujeitos, vamos nos referir aos entrevistados e, quando falamos de professores, estamos incluindo nessa indicação professores e professoras. [...] O grupo pesquisado, respectivamente a cada colégio que atua foi selecionado considerando o tempo de serviço, a disciplina na qual atua e o sexo, sendo o número de professores equivalentes para cada aspecto considerado. A maioria dos sujeitos trabalha em dois ou até mesmo nos três Colégios pesquisados (DOTTA, 2006, p. 50-51).

Notemos que Dotta não especifica o número de professores e professoras entrevistados e também o tempo de profissão destes mesmos, dados importantíssimos para um trabalho dessa natureza. Devemos considerar que o magistério na Educação Infantil é um campo majoritariamente feminino, quando não, exclusivamente. Isso pode trazer para o trabalho uma carência de representações sociais masculinas, que obviamente devem ser consideradas numa pesquisa com este escopo. Também sentimos falta, na caracterização do grupo, de elementos que possam mostrar o contexto histórico e cultural no qual o grupo está inserido, tais informações enriqueceriam o trabalho no sentido de possibilitar no grupo a visão da pesquisadora, na tessitura de seu trabalho, de mais conexões além do fato de serem professores e professoras.

De fato, na leitura do trabalho faz falta sabermos o número de professores e o número de professoras. Sabemos que são profissionais de três escolas de Palotina no Paraná. Entretanto, não temos uma descrição econômica ou sociocultural da cidade. Enfim, dados que permeiam a vida desses professores e professoras e que poderiam dar à autora mais possibilidades de interpretação. Por seu turno, Dotta faz um agrupamento de respostas à pergunta: Para você, o que é ser professor? Em três grupos principais:

[...] fizemos um primeiro agrupamento de respostas segundo a frequência(sic) ser professor no âmbito da participação no crescimento do aluno, na sua preparação para o futuro envolvendo o lado pessoal profissional e/ou profissional deste; o segundo grupo envolveu as questões ligadas ao conhecimento: o ser professor que é ensinar e ao mesmo tempo aprender, ensinar e aprender conteúdos e métodos. Um terceiro agrupamento foi estabelecido considerando as questões ligadas ao sentimento com relação à profissão, sentimentos de satisfação e insatisfação. Embora essa questão não esteja ligada diretamente ao ser professor, permeou as respostas da maioria dos sujeitos (DOTTA, 2006, p. 53).

Duas questões são importantes sobre esse quesito: em primeiro lugar, 
consideramos importante ponderar afirmação da autora de que as questões ligadas à insatisfação não estejam ligadas diretamente ao ser professor. Se essa questão permeou as respostas da maioria dos sujeitos, como frisa a autora, como pode não estar ligada ao "ser professor"? A nosso ver, é parte constitutiva desse ser professor(a) na temporalidade e no espaço circunscrito da pesquisa. Em segundo lugar: após exemplificar cada um dos grupos citados acima com trechos dos depoimentos, a autora afirma que: "Considerando os três agrupamentos de respostas, é possível perceber que de fato não existem diferenciações significativas ou algum tipo de resposta comum levando em conta o local de atuação, tempo de serviço, disciplina que atua ou sexo (DOTTA, 2006, p. 59)." Tal interpretação ganharia mais força se os leitores também tivessem acesso, na caracterização do objeto, às informações de sexo, disciplina de atuação e tempo de serviço.

Dito isso, resta o capítulo que a autora faz análise dos dados, o terceiro. Dos três grupos mencionados acima, a autora extrai duas categorias: a) relações que o professor estabelece com o saber e o fazer e b) relações que o professor estabelece com o ser e o sentir. Os sentimentos com relação à satisfação e insatisfação com a profissão são considerados por Dotta como elementos que perpassam as duas categorias. A citação abaixo pode ser uma tanto longa, entretanto a consideramos necessária, pois a autora constrói uma formulação interessante sobre essas noções, de satisfação e insatisfação, encontradas nos depoimentos.

As duas categorias são transpassadas por elementos que evoluem os sentimentos de satisfação e prazer, insatisfação e dificuldades. Na categoria que envolve as relações com o saber e o fazer, a satisfação está em ver o aluno aprender, no relacionamento com o aluno, no aprender (o professor se transformando), e as dificuldades são definidas pelos baixos salários, condições de trabalho nem sempre adequadas, indisciplina dos alunos. Já na categoria das relações que o professor estabelece com o ser e o sentir, está a satisfação de ver o aluno modificado; nesse caso, a satisfação já ultrapassa o período de relação direta com o aluno na escola, pois é ver o aluno pai ou mãe de família, advogado, dentista, professor. A insatisfação está na falta de reconhecimento, de valorização social do professor, que gera um sentimento de frustração. O que se pode perceber nessa reclamação quanto à falta de valorização social do professor é que não seria uma desvalorização ligada à questão de baixos salários e condições de trabalho ruins. Existe uma ligação sim com esses aspectos, mas o que prevalece é a perda daquela imagem do professor que 
antigamente era respeitado por todos, que ocupava um lugar de prestígio na sociedade (DOTTA, 2006, p. 64).

Da citação acima, podemos depreender que incomoda aos professores do universo pesquisado mais os aspectos simbólicos que os materiais na sua prática profissional. Independente da interpretação de Dotta, nos indagamos se a autora ainda chegaria a essa conclusão levando em conta os elementos mencionados acima de caracterização do objeto, sexo, disciplina de atuação e tempo de profissão.

Pensando de modo mais amplo, nas questões materiais e simbólicas mencionadas na citação, será possível separar estas duas facetas da profissão. Entendemos esse tal apego a um passado em que professores gozavam de respeito e consideração como uma forma de pensar explicitada pela formulação de vivemos em um presente de couro, porém presos a um passado de ouro. Mas, muitas vezes não nos damos ao trabalho de realmente tentar saber como eram de fato as condições reais dos professores do passado e quais foram as diretrizes políticas adotadas em nosso país no setor educacional, assim, nos apegamos à imagem que guardamos, cristalizada na memória, sobre nossos mestres. E nesse caso, esta imagem parece ser a de profissionais respeitados e considerados, o que nos leva à seguinte questão: tal reconhecimento e "prestígio", de que os professores se sentem alijados, pode ser conseguido sem melhores salários e condições de trabalho?

De forma geral, Dotta sintetiza as representações que encontrou nos professores da seguinte forma: a) ser professor é ensinar e aprender. b) ser professor é participar da construção da história do aluno enquanto pessoa e profissional. c) ser professor é gostar do que faz, ter prazer e satisfação sem desconsiderar as dificuldades (DOTTA, 2006, p. 67). A autora considera que esses elementos destacados estão ligados à identidade do ser professor, uma identidade que se constrói nos momentos de formação inicial ou nas oportunidades de formação continuada. São nesses mesmos momentos, então, que essas representações podem se alterar. Tal afirmação faz nos questionarmos se a identidade do "ser professor" pode se constituir também na sua prática profissional.

Lembremos que as duas categorias de respostas a que a autora chega na depuração dos dados coletados, as relações com o saber e fazer e as condições precárias para realização do trabalho, e falta de reconhecimento, só podem derivar de percepções forjadas na prática profissional dos professores. Em ocasiões de formação ou numa entrevista, estas percepções e sentimentos 
formadores de identidade podem ser formulados, mas, é difícil acreditar que sejam fruto exclusivo destes momentos. Porém, enfrentando salas de aulas lotadas, mal ventiladas, sentindo cada vez mais a perda de sua autonomia ou, simplesmente, encontrando um antigo aluno com sua família no supermercado, podemos ter também momentos formadores de identidade?

Esperamos que os apontamentos acima possam auxiliar outros pesquisadores nos seus trabalhos. Convém reiterar que se trata de obra com bom embasamento teórico e que quando se trabalha com representações sociais uma minuciosa caracterização do objeto é necessária. Principalmente por se tratar de um arcabouço teórico/metodológico extremamente fértil e que pode contribuir muito para investigações sobre os processos de formação das identidades de professores e professoras.

Data de recebimento: 27.04 .2020

Data de aceite: 12.07 .2020 